\title{
Arbor
}

\section{La Psicología de Don Quijote de la Mancha y el Quijotismo}

\section{Santiago Ramón y Cajal}

Arbor CLXXIX, 705 (Septiembre 2004), 1-12 pp.

«Universalmente admirada es la soberbia figura moral del hidalgo manchego. D. Alonso Quijano el bueno, convertido en andante caballero por la sugestión de los disparatados libros de caballería, representa, según se ha dicho mil veces, el más perfecto símbolo del honor y del altruismo. Jamás el genio anglo-sajón, tan dado á imaginar caracteres enérgicos y originales, creó personificación mas exquisita del individualismo indómito y de la abnegación sublime.

Pero puntualicemos brevemente los rasgos psicológicos sobresalientes del protagonista de la novela inmortal. Como nos refiere su creador, Don Quijote se entrega ansiosamente á la lectura de novelas caballerescas, hasta el punto «de olvidar la administración de su hacienda". Y del poco dormir y del mucho leer y cavilar, se le seca el cerebro y se le perturba el juicio. En medio de su exaltación intelectual y afectiva, cae en la cuenta que, por culpa del egoísmo humano, gime el mundo en la iniquidad y el deshonor; y así, pasando de la idea á la acción, abandona las dulcedumbres y blanduras del hogar y sale á campaña resuelto a «enderezar entuertos, amparar doncellas y pupilos y castigar agravios».

Siente hacia la especie esa pasión generosa y desbordante de los grandes iniciadores religiosos, y quiere demostrarla "poniéndose en ocasión de peligros donde acabándolos cobre eterno nombre y fama». Todo lo da por bien empleado con tal de "atender al aumento de su honra y al servicio de la república", sin codiciar más galardón que el recuerdo agradecido de la posteridad y la mirada amorosa y pía de la señora de sus pensamientos. Cuando en sus dolorosas desaventuras cae vencido por aciago destino, no siente el dolor en la piel, sino en el ideal. Pero las derrotas no 
entibian su fe; créese perseguido por envidiosos y malignos encantadores, y espera ablandarlos á fuerza de constancia y de heroísmo, ó recibir la ayuda de genios propicios y generosos con el valor desgraciado. En vano los equilibrados y sesudos Carrascos y Mirandas, defensores de los fueros del sentido común, le advierten del peligro y le llaman á la realidad prosáica y amarga: Don Quijote no los oye, y si á veces discute con ellos, es solamente cediendo á las inexcusables leyes de la cortesía y de la buena crianza. ¿Qué pueden decirle que supere al excelso ideal que lleva en el cerebro? En comparación del grandioso y mirífico ensueño, donde los hombres son héroes de leyenda, la naturaleza, áurea trama tejida por hadas, las mujeres, arquetipos de belleza y de soberana euritmia, ¿qué vale el pálido y mezquino mundo real? ¡Una vida interior, intensa, exclusiva y arisca le absorbe; vida recogida y ensimismada de larva ocupada en hilar impasible, entre los bramidos del trueno y los furores del viento, el áureo capullo de la gloria!...

Todos los grandes soñadores aspiran á realizar sus ensueños, á vestir sus quimeras de carne y sangre, lanzando al mundo un tipo humano diferente y superior al actual, creador de una corriente de vida poderosa y arrolladora de las barreras levantadas por el sentimiento, el interés y la tradición. Diríase que es la idea que aspira á cuajarse en materia; que, surgida en el cerebro como eco lejano de la realidad, pugna por remontarse á su fuente y erigirse en tirana y maestra de la naturaleza misma.

Esta importante ley psicológica, bien conocida de Cervantes, cúmplese en don Quijote. También éste acaricia un ensueño luminoso y quiere vivirlo y hacerlo vivir á los demás, hermoseando y ennobleciendo la tierra con sus mágicos destellos. Durante su ardiente apostolado, no recurrirá á la sugestión y al milagro, recursos dialécticos del manso propagandista religioso, sino á las violencias de la contradicción y á los rigores de la espada. Nada de cobardes componendas con las insidias é iniquidades de los fuertes. De dura roca son las conciencias y á botes de lanza deben esculpirse. Y él las esculpirá con arreglo al modelo ideal del honor aprendido en las heroicas historias. Porque Don Quijote, á más de poseer un yo hipertrófico, desbordante de voluntad y de energía, se siente fortalecido por esa fe ciega en la fortuna característica de los grandes conquistadores de almas y tierras.

Si á tan admirable encarnación de la religión del deber y del altruismo no hubiera añadido Cervantes algunos rasgos patológicos, el tipo de Don Quijote, con ser de contextura ciclópea, habría quedado reducido á las modestas proporciones de un filósofo práctico, un tanto exaltado é imbuído en arrogante confianza en su buena estrella y en la excelsitud de 


\section{La Psicología de Don Quijote de la Mancha y el Quijotismo}

su misión. Pero Cervantes - no hay que olvidarlo- se propuso ante todo una obra de polémica literaria. Queriendo esgrimir el arma poderosa del ridículo contra los libros de caballerías, juzgó al efecto indispensable desconceptuar y achicar un tanto, con el estigma de la locura, la simpática figura del ingenioso hidalgo, cuyo entendimiento agudísimo y genial fue presa y juguete de ilusiones, alucinaciones, obsesiones é ideas delirantes.

Más de una vez me he preguntado: ¿por qué Cervantes no hizo cuerdo a su héroe? La defensa briosa y elocuente del realismo en la esfera del arte, no exigía necesariamente la insania del caballero del ideal. Convengamos, empero, en que un Quijote meramente filántropo, aunque apasionado y vehemente, no habría abandonado de buen grado las blanduras y regalos de la vida burguesa para lanzarse á las arriesgadas y temerarias aventuras. Y aun dado caso que la codicia de gloria y el ansia de justicia fueran poderosas á sacarle de sus casillas, llevándole á militar denodadamente contra el egoísmo y la perfidia del mundo, ¿habrían dado pie sus gestas, en tanto que materia de labor artística, para forjar los épicos, maravillosos y sorprendentes episodios que todos admiramos en el libro inmortal y que tan alto hablan del soberano ingenio y vena creadora del Príncipe de nuestros prosistas?

Sin duda, á causa de esta obligada anormalidad mental de Don Quijote, que le llevaba á provocar las más descomunales é imposibles aventuras, el tono general de la novela es de honda melancolía y desconsolador pesimismo. En vano el lector, emocionado, pretende serenarse haciéndose cuenta que Cervantes no personificó en el Caballero de la Triste figura sino las desvariadas, inconsistentes é inverosímiles composiciones caballerescas. Arrastrados, á nuestro pesar, por la tendencia generalizadora de la razón, nos asalta el temor de que el anatema que en la obra de Cervantes pesa sobre el arte romántico, se extienda á dominios ajenos al designio del soberano artista. Y nos preguntamos, con inquietud en el alma y lágrimas en los ojos: ¿Cómo? ¿Estarán también condenados á perecer irremisiblemente todos los altos idealismos de la ciencia, de la filosofía y de la política? ¿Reservado queda no más á la demencia afrontar los grandes heroísmos y las magnas empresas humanitarias?

Y esta emoción melancólica y deprimente llega á la agudeza al ver cómo, a la hora de la muerte, el loco sublime, convertido ya en Alonso Quijano el bueno, recobra bruscamente la razón para proclamar la triste y enervadora doctrina de la resignación ante las iniquidades del mundo. En los nidos de antaño no hay pájaros hogaño, nos dice con voz desfallecida, en que parecen vibrar extertores de agonía. ¡Arranque de infinita desilusión, que nos anuncia cómo el paraíso de paz y de ventura y la en- 
soñada edad de oro que la humanidad anhela para el presente ó para no muy alejado porvenir, representa un remotísimo pasado que ya no volverá!...

Necio fuera desconocer que, no obstante la nota general hondamente patética, campea y retoza en la epopeya cervantina un humorismo sano y de buena ley. ¿Qué otra cosa representa el donairoso y regocijado tipo de Sancho, sino el artístico contrapeso emocional del quejumbroso y asendereado Caballero de la Triste figura?

Reflejo fiel de la vida, sucédense en la inmortal novela, como en el cinematógrafo de la conciencia humana, estas dos emociones antípodas y alternantes: el placer y el dolor. Pero, al modo de esos frutos de dulce corteza y amargo hueso, en la creación cervantina la acritud es interna y el dulzor externo. Cierto que hay peripecias y coloquios de una vis cómica incomparable; mas, á despecho de la intención piadosa del autor, bajo la ingenua y blanca careta del gracioso, corren calladas las lágrimas, cual silencioso arroyuelo que bajo la soleada nieve se desliza.

¿Cómo se forjó, allá en la caldeada imaginación Cervantina, tan felicísimo y artístico contraste? ¿En virtud de qué condiciones psicológicas escritor tan sereno, quijotil y optimista puso en su obra ese dejo de tristeza y de amargo pesimismo? Cuestiones arduas y dificilísimas, para cuya solución fuera imprescindible conocer todos los repliegues y recovecos de la complicada mente de Miguel, amén de los choques, episodios é incidentes emocionales que la conmovieron y adoctrinaron durante los años tristes precursores de la genial concepción.

Con todo eso, no faltan valiosos materiales que permitan, si no resolver el problema, formular al menos alguna posibilidad más ó menos plausible. Estos datos, acarreados por los penetrantes análisis de nuestro primer crítico Menéndez Pelayo, por la diligencia y saber de Revilla y Valera, por la reciente labor tan copiosa, artística y evocadora de Navarro Ledesma, por los atisbos felices de Unamuno, Salillas y otros muchos expertísimos y devotos cervantistas, nos enseñan que Cervantes, salvo el paréntesis realista durante el cual planeó y escribió el libro inmortal, fue siempre Quijote incorregible en la acción y poeta romántico en el sentir y pensar.

¿Qué ocurrió, pues, para que el manco de Lepanto abandonara el culto de sus ideales artísticos? Fácil es adivinarlo, y, por otra parte, consignado aparece en no pocos estudios críticos.

Nació y se crió Cervantes con altas y nobilísimas ambiciones. Héroe en Lepanto, soñó con la gloria de los grandes caudillos; escritor sentimental y amatorio, ansió ceñir la corona del poeta; íntegro y diligente 
funcionario, aspiró acaso á la prosperidad económica, o cuando menos al aurea mediocritas; enamorado de Esquivias, pensó convertir su vida en dulce y perdurable idilio. Mas ¡ay!, el destino implacable trocó sus ilusionés en desengaños, y al doblar de la cumbre de la vida se vio olvidado, solitario, pobre, cautivo y deshonrado...

Los grandes desencantos desimantan las voluntades mejor orientadas y deforman hasta los caracteres más enteros. Tal le ocurrió á Cervantes. De aquel caos tenebroso de la sevillana cárcel, donde se dieron cita para acabar de cincelar al genio cuantas lacerías, angustias y miserias atormentan y degradan á la criatura humana, surgieron un libro nuevo y un hombre renovado, el único capaz de escribir este libro. ¡Obra sin par, amasada con lágrimas y carne del genio, donde se vació por entero un alma afligida y desencantada del vivir!

Sus páginas son símbolo perfecto de la vida. Como en el corte de un bosque, abajo vemos las negruras del humus vegetal formado con detritus de ilusiones y despojos de esperanzas (propio alimento del genio literario); sobre la tierra, erguidos y mirando al cielo los robustos tallos de las ideas levantadas, de los propósitos nobles, de las aspiraciones sublimes; y arriba, bañadas en la atmósfera azul, las frondas del lenguaje natural, castizo y colorista, la delicada flor de la poesía y el acre fruto de la experiencia.

Se ha dicho por muchos que la suprema creación cervantina es el más perfecto, el último, el insuperable libro de caballerías. Mas en juicio semejante, á primera vista paradójico, y en pugna con la finalidad confesada de la obra, y las explícitas declaraciones del mismo Cervantes, yo sólo acierto á ver la tácita afirmación de que la figura del protagonista está tan soberana, tan amorosamente sentida y dibujada, que por fuerza el autor debió tener algo y aun mucho de Quijote. No salen de la pluma tan perfectos y vivos los retratos humanos si el pintor no se miró muchas veces al espejo y enfocó los escondrijos de la propia conciencia. Pero después de reconocer este parentesco espiritual entre Don Quijote y su autor, es forzoso convenir también en que, en la incomparable novela, á vueltas de algún ritornello á las antiguas caballerescas andanzas, campean y se exteriorizan, con elocuentes acentos, el desaliento del apasionado del ideal, el doloroso abandono de una ilusión tenazmente acariciada, el mea cul$p a$, un poco irónico quizá, del altruismo desengañado y vencido.

Para conservar serena la mente y viva y plástica la fantasía, menester es que el poeta desgraciado evoque de cuando en cuando imágenes risueñas capaces de ocultar y engalanar el fondo tenebroso de la conciencia, al modo como la irisada espuma disimula el oscuro é insondable 
piélago. Compensación emocional de este género, representa, en mi sentir, el humorismo de Sancho Panza. En tan felicísima encarnación de la serenidad y de la bondad del alma, halló Cide Hamete el sosiego y la fuerza indispensables para proseguir su labor creadora y descartar visiones sombrías y punzantes remembranzas.

¡Yo te saludo, pues, Sancho el pacífico, Sancho el bueno, Sancho el jovial! En las páginas de la imperecedera epopeya no simbolizas tan sólo la baja meseta del sentido común, el saber humilde del pueblo acuñado en refranes, el lastre, sin el cual el hinchado globo del ideal estallara en las nubes. Tu eres algo más y mejor que todo eso. Con tus gracias, socarronerías y donaires solazaste el espíritu de Cervantes, haciéndole llevadera la carga abrumadora de angustias y desventuras. Por ti amó la vida y el trabajo, y pudo, tiempos adelante, y curado de enervadores pesimismos, retornar á los románticos amores de la juventud, componiendo el Pérsiles, verdadero libro de caballerías, y el Viaje al Parnaso, admirable y definitivo testamento literario. ¡Beleño suave de su sensibilidad sobreexcitada, tú salvaste al genio, y, con él, su gloria y nuestra gloria!

Más de una vez, deplorando la amargura que destilan las páginas del libro cervantino, he exclamado para mis adentros: ¡Ah! Si el infortunado soldado de Lepanto, caído y mutilado al primer encuentro, no hubiera devorado desdenes y persecuciones injustas; si no llorara toda una juventud perdida en triste y oscuro cautiverio; si, en fin, no hubiera escrito entre ayes, carcajadas y blasfemias del hampa sevillana, en aquella infecta cárcel donde toda incomodidad tenía su asiento..., icuán diferente, cuán vivificante y alentador Quijote hubiera compuesto! Acaso la novela imperecedera sería, no el poema de la resignación y de la desesperanza, sino el poema de la libertad y de la renovación. Y quién sabe si, en pos del $C a$ ballero de los Leones, otros Quijotes de carne y hueso, sugestionados por el héroe cervantino, no habrían combatido también en defensa de la justicia y del honor, convirtiéndose al fin la algarada de locos en gloriosa campaña de cuerdos, en apostolado regenerador, consagrado por los homenajes de la historia, y el eterno amor de Dulcinea..., de esa mujer ideal, cuyo nombre, suave y acariciador, evoca en el alma la sagrada imagen de la patria!...

Pero en seguida, al dar de esta suerte rienda á mi desvariada fantasía, atajábame una duda inquietante. ¿Estás bien seguro -me decía- de que en un ambiente sereno y tibio, exento de pesadumbres y miserias, se habría escrito el Quijote?

$\mathrm{Y}$ de haber visto la luz en menos rigurosas condiciones de medio moral, ¿fuera, según es ahora, resumen y compendio de la vida humana, y 
visión histórica fidelísima, donde, simbolizadas en tipos universales y eternos, se agitan y claman todas las lacras, pobrezas y decadencias de la España vieja?

¡Oh, qué gran despertador de almas é instigador de energías es el dolor! Comparable á enjambre de marinos noctilucos cuya fosforescencia se exalta al choque de la hélice del navío, las perezosas células cerebrales sólo encienden su luz bajo el látigo de las emociones penosas. ¡Quizás el privilegiado cerebro de Cervantes necesitó asimismo, para llegar al tono y hervor de la inspiración sublime, de la punzante espuela del dolor y del espectáculo desolador de la miseria!

Hora es ya de decir algo del quijotismo. Cuando un genio literario acierta á forjar una personificación vigorosa, universal, rebosante de vida y de grandeza, y generadora en la esfera social de grandes corrientes de pensamiento, la figura del personaje fantástico se agiganta, trasciende de los límites de la fábula, invade la vida real y marca con sello especial é indeleble á todas las gentes de la raza ó nacionalidad a que la estupenda criatura espiritual pertenece. Tal ha ocurrido con el héroe del libro de Cervantes.

Muchos extranjeros, y no pocos españoles, creyendo descubrir cierto aire de familia entre el citado protagonista y el ambiente moral en que fué concebido, no han reparado en adjudicarnos, sin más averiguaciones, el desdeñoso dictado de quijotes, calificando asimismo de quijotismos cuantas empresas y aspiraciones españolas no fueron coronadas por la fortuna. Complácense en pintarnos cual legendarios Caballeros de la Triste figura, tenazmente enamorados de un pasado imposible, é incapaces de acomodación á la realidad y á sus útiles y salvadoras enseñanzas.

No seré yo, ciertamente, quien niegue la complicidad que, en tristes reveses y decadencias, tuvieron la incultura, así como la devoción y el apegamiento excesivos á la tradición moral e intelectual de la raza; pero séame permitido dudar de que la ignorancia, el aturdimiento y la imprevisión constituyan la esencia y fondo del quijotismo. Ó esta palabra carece de toda significación ética precisa, ó simboliza el culto ferviente á un alto ideal de conducta, la voluntad obstinadamente orientada hacia la luz y la felicidad de la humana colmena. Apóstoles abnegados de la paz y de la beatitud sociales, los verdaderos Quijotes siéntense abrasados por el amor á la justicia, para cuyo triunfo sacrifican sin vacilar la propia existencia, cuanto más los apetitos y fruiciones de la sensibilidad. En todos sus actos y tendencias ponen la finalidad, no dentro de sí, en las bajas regiones del alma concupiscente, sino en el espíritu de la persona colectiva, de que se reconocen células humildes y generosas. 


\begin{abstract}
Ahora bien, ¿quién, por mediano conocedor que sea de la historia moderna, hábitos y tendencias de la actual gente española, osará calificarnos de Quijotes? Los hubo y los hay, sin duda, entre nosotros; pero jah!, cuán pocos, cuán oscurecidos y desdeñados!

Si tuviéramos espacio suficiente, fácil nos sería demostrar cuán raramente aparecieron en nuestra historia esos genios que Emerson designa hombres representativos (y que yo llamaría hombres de la especie, porque, limpios de bajos egoísmos, á la especie se dan y por ella perecen). Aunque nos duela en el alma el confesarlo, es fuerza reconocer y declarar que á España, si le sobraron los Sanchos, le faltaron á menudo los Quijotes.

¿Cómo? -se dirá-; los españoles que descubrieron y conquistaron la América; los que fueron generosos de su sangre combatiendo en pro del catolicismo en buena parte de Europa; los que dieron tan gallardas muestras de lealtad acrisolada á sus Reyes y de amor acendrado a su Patria, ¿no rindieron culto á la abnegación, ni aspiraron á un ideal de humanidad, de magnanimidad y de justicia?

Ciertamente, injusto y antipatriótico sería desconocer que hubo un tiempo en que la Iberia rindió copiosa cosecha de Quijotes en todas las direcciones de la humana actividad. Á esta casta pertenecieron señaladamente no pocos descubridores y conquistadores de América y Oceanía, en cuyas rudas é ingenuas naturalezas concurrían rasgos exquisitamente quijotiles: la sed devoradora de gloria, el desprecio á la vida, y la sana ambición de poder y de mando; pasiones que, templando y sublimando caracteres que parecen arrancados de las Vidas de Plutarco, obraron verdaderos prodigios. Abundaban, sin duda, entre aquellos férreos guerreros, aventureros crueles, codiciosos, antes dispuestos á acaparar riquezas é imponer tiranías, que á enaltecer y honrar el nombre de la Patria y de su Rey. Mas, por encima de tan disonantes y antisociales instintos, descollaban dos pasiones, muy bien avenidas con el quijotismo honrado, á saber: la energía de la voluntad indomable y el ansia de nombradía. Tan abundante fué en aquellos felices tiempos el capital conquistado por el heroísmo, que sin ser después acrecentado, antes bien sufriendo importantes mermas, pudo España mantenerse respetada, próspera y gloriosa cerca de un siglo.

Por desgracia, aquellos hombres enamorados de la vida y de la acción, descubridores y debeladores de inmensos continentes, dejaron una prole despreciadora de la tierra y exclusivamente ambiciosa de celestiales y be atíficas ínsulas. Refugiados en las austeridades de la religión, huidos del mundo y de sus glorias, los Quijotes cruzaron pocas veces el Atlántico en busca de dramáticas y novelescas hazañas. De Sanchos se iban progresi-
\end{abstract}


vamente poblando las Colonias, y, lo que fue peor, regidas por Panzas fueron, ó á lo sumo por sesudos, morigerados y egoístas Caballeros del Verde gabán. Y cuando el rústico y bonachón escudero se encontró solo, huérfano y nostálgico de los sabios consejos y del esfuerzo heroico de Don Quijote, las baratarias ínsulas se perdieron, y el pobre y mustio pejugalero, vuelto al pardo y terroso lugar, reducido quedó, acaso para siempre, a los infecundos páramos manchegos...

No son, con todo eso, el arte de la guerra y los empeños de la expansión geográfica, los órdenes de la actividad nacional donde más escasearon los grandes arranques del corazón y el espíritu idealista. Harto más huérfanos de alentadores y excelsos quijotismos, quedaron los dominios del arte, de la filosofía y de la ciencia.

Pese á los juicios poco compartidos de ciertos críticos, la verdad histórica obliga á reconocer que el arte español, en sus variadas manifestaciones, fué esencialmente humano y realista. Por lo que toca á la poesía, la musa nacional mostróse tan hostil al romanticismo y á la hipérbole, que, hasta en la gloriosa epopeya del Romancero, inspirada en las épicas hazañas de la reconquista, no traspasó nunca los discretos límites de la narración histórica. Como afirma la gran autoridad de Menéndez Pelayo, aludiendo al poema del Cid, «nuestra épica está limpia de toda aspiración quimérica y es sumamente parca en el empleo de lo maravilloso...» «Las hazañas atribuidas á los héroes por la musa popular, son poco más o menos las mismas que ejecutaron en el mundo» [1].

Notorio es, por otra parte, que las poesías pastoriles y los libros de caballerías fueron en su origen producciones exóticas, tardíamente inoculadas en el alma nacional, y extrañas de todo punto á nuestro peculiar genio literario, el cual, menos alejado del clasicismo que del idealismo, supo mantenerse fiel, salvo algunos coqueteos románticos y bucólicos, á su íntima tendencia realista y utilitaria. Sólo el pueblo, doquier propenso á lo trágico, maravilloso é inverosímil, como perpetuo niño que es, se entregó con ardor á la lectura de los libros y romances caballerescos; y aun hoy sucede lo mismo y sucederá siempre, mientras nuevas organizaciones sociales no permitan que el eterno infante evolucione, llegando, para los efectos artísticos, á la mayor edad.

El mismo Don Quijote, con todo y ser la obra de un romántico impenitente, ¿qué representó en su tiempo, abstracción hecha de sus intrínsecos primores y soberanas armonías, sino la reacción poderosa y esencialmente conservadora del realismo nacional castizo contra los extraviados y forasteros idealismos? 
Más yermo aún de grandes abnegaciones y de levantados quijotismos se nos presenta el campo de la ciencia y la filosofía españolas. Enamorados de libros viejos, y ajenos á la inmensa renovación espiritual que trajo el renacimiento á todas las esferas del saber, la mayoría de nuestros pensadores y científicos limitábanse, por lo común, á aplicar modestamente los teoremas matemáticos y los hechos físicos y biológicos descubiertos por extranjeros, á la geografía, al arte de la navegación, á la metalurgia, á la industria guerrera y al arte de curar. Exceptuados sabios como Azara, Servet, Gómez Pereira, Huarte, Vives, y algunos otros, en que fulguran, de cuando en cuando, relámpagos de fuego creador ó intuiciones geniales, nuestros científicos hicieron siempre gala de desdeñar los temas de pura investigación, las verdades especulativas despojadas de aplicación útil; sin echar de ver, según les ocurre hoy mismo á muchos intelectuales, que la ciencia llamada práctica está indisolublemente unida á la abstracta ó idealista, como el arroyo á su manantial. ¡Extraña aberración, propagada por la rutina, y tan vituperable, como sería la del labrador que diera en la manía de arrancar las flores para acrecentar los frutos! ¡Cómo habría de medrar el jardín de nuestra cultura, si nos hemos pasado cuatro mortales siglos desdeñando ó arrancando la flor de las ideas! [2].

Igual deplorable ausencia de salvadores quijotismos se advierte con pena en esos dominios en donde el sentimiento romántico y el ansia de lances novelescos y extraordinarios se asocia felicísimamente á los más elevados intereses de la civilización y de la política. Adivináis, sin duda, que aludo á los viajes científicos de exploración á que, en días mejores, se debió la prosperidad y renombre de la patria. Quisiera equivocarme, pero yo no conozco ninguna expedición geográfica al polo Norte ó Sur emprendida por españoles ó hispano-americanos; mientras que por docenas se cuentan las gloriosas empresas de este género intentadas ó realizadas por yanquis, ingleses, suecos, alemanes, rusos y hasta italianos. ¡Triste es confesarlo; pero ello es que el pálido sol de media noche no realzó jamás, con sus poéticos rayos, los pliegues de la española bandera! [3].

Á las puertas mismas de la patria álzase el África tenebrosa, solar de la hispana raza al decir de sabios antropólogos. Acostada sobre la ribera mediterránea, parece mirarnos amorosa cual inmensa y misteriosa esfinge que invita á escrutar hondos arcanos y á meditar en épicas empresas. Pero ¡ah! en vano espera siglos hace la ingenua Dulcinea al Caballero de los Leones. ¿Cuándo arribarán á las africanas playas Quijotes geógrafos, naturalistas ó guerreros, capaces de aportar, con los trofeos de la observación científica ó los relatos de romancescas hazañas, los únicos 


\section{La Psicología de Don Quijote de la Mancha y el Quijotismo}

títulos de propiedad que los pueblos cultos estiman hoy suficientemente justificativos del condominio colonial?

Y convirtiendo la atención á más vulgares empresas, ¿dónde están los Quijotes de nuestra industria y comercio? ¿No es doloroso y desconsolador espectáculo el ver cómo nuestros opulentos industriales desdeñan ó descartan de sus fábricas á la ciencia, poderosa palanca impulsora á la hora actual de inmensos progresos fabriles, y se concretan modestamente (sin asomos de esa previsión lejana característica de los prudentes egoísmos) á importar y á explotar sórdidamente las máquinas y procedimientos exóticos, viviendo al día, sin lucha y sin gloria, en la mezquina incubadora del arancel y de los cambios?

Labor de alta pedagogía y de verdadera regeneración es corregir en lo posible los vicios y defectos mentales, entre los cuales, acaso el más fértil en funestas consecuencias sociales es la escasez de civismos nobles y desinteresados, de sanos y levantados quijotismos en pro de la cultura, elevación moral y prosperidad duradera de la raza.

Admiremos el libro de Cervantes, pero no derivemos su moraleja hacia dominios á que no tendió el ánimo del autor. El realismo en el arte, ni deja de admitir cierta discreta dosis de levadura romántica, á fin de excitar el interés y elevar los corazones, ni contradice el supremo y patriótico fin de imprimir á la filosofía, á la ciencia y á la industria rumbos resueltamente idealistas.

El quijotismo de buena ley, es decir, el depurado de las roñas de la ignorancia y de las sinrazones de la locura, tiene, pues, en España ancho campo en que ejercitarse. Rescatar las almas encantadas en la tenebrosa cueva del error; explorar y explotar, con altas miras nacionales las inagotables riquezas del suelo y del subsuelo; descuajar y convertir en ameno y productivo frutar la impenetrable selva de la Naturaleza, donde se ocultan amenazadores los agentes vivos de la enfermedad y de la muerte; modelar y corregir, con el buril de la intensa cultura, nuestro propio cerebro, para que en todas las esferas de la humana actividad rinda copiosa mies de ideas nuevas y de invenciones provechosas al aumento y prosperidad de la vida: he aquí las estupendas y gloriosas aventuras reservadas a nuestros Quijotes del provenir.

Consideradas desde el punto de vista moral, son las naciones síntesis supremas de ensueños y aspiraciones comunes, sublime florecimiento de una planta cuyas múltiples raicillas se extienden y nutren por todos los corazones. De buena gana compararía yo también los grandes pueblos á esas poéticas islas de coral que emergen del mar en las augustas soledades oceánicas. Si, con soñadores ojos de artista, os embelesáis contem- 
plando las rientes y apacibles costas festoneadas de blancas espumas, las flores peregrinas y fragantes, los colosales árboles cuyas copas semejan cimbreante coro de las aves del cielo, pensaréis que aquel paraíso surgió espontáneamente por extraño capricho de Amfítrite; pero examinad el subsuelo con el reposado análisis de la ciencia, descended al fondo del mar (lo que vale tanto como remontarse en la Historia), y al sorprender en los calcáreos colosales estribos la obra y las reliquias de miriadas de seres ínfimos y obscuros, comprenderéis que todo aquel grandioso florecimiento de lo alto representa la construcción secular y obstinada de innumerables y abnegadas existencias.

He dicho».

\section{Notas}

1 Salillas cita también estos juicios de Menéndez Pelayo, justificando la tesis de que el alma nacional, heróica, robusta y sana en nuestro siglo de oro, degeneró más adelante en los alardes é impotencias del matonismo y de la picaresca.

2 Justo y patriótico es proclamar que la España científica del siglo XVI inició muchas investigaciones y entrevió luminosas y fecundas verdades; mas, por desdicha, acabó y perfeccionó pocas teorías, porque faltaron á sus hombres, con el ansia de gloria internacional, pasión eminentemente quijotil, el esfuerzo supraintensivo de la atención y la perseverancia infatigable. Doloroso es ver á filósofos tan esclarecidos como Gómez Pereira, Vives, Francisco Vallés, Fox Morcillo, etc, formular antes que nadie los principios del mé todo experimental, pero sin demostrar con hechos su eficacia; al famoso Arias Montano explicar la ascensión del agua en los tubos por la presión atmosférica, sin llegar, empero, á las leyes de Torricelli y Pascal; á Pérez de Oliva, profesor de Luz y Magnetismo en Salamanca (1533), anunciar la posibilidad de servirse del magnetismo para la comunicación entre personas ausentes y distantes, sin llegar con todo á ningún descubrimiento importante en la materia; á Pedro de Liria, adivinar la existencia de un polo magnético á pocos grados de distancia del geográfico, sin precisar, mediante observaciones suficientes, su posición; a Juan de Escribano, traductor de Porta, contentarse con presagiar la importancia práctica de la fuerza elástica del vapor, etc., etc. Contribuyó, sin duda, á esta escasez de resultados, la manía enciclopédica, que si crea cimas en para descubrir amplios horizontes, empequeñece también los objetos vistiéndolos de nieblas. Enciclopedistas, al par que grandes pedagogos y comentaristas, fueron el citado Arias Montano, el Brocense, Pedro Ciruelo, Nebrija, Santa Cruz, etc., y, precisamente por serlo, resultaron, en lo tocante á los frutos científicos conseguidos, inferiores á su genio.

3 Aunque tales empresas, á primera vista baldías, no condujeran á la solución de interesantes problemas geográficos, meteorológicos y físicos, constituirían siempre una gimnasia del heroísmo, indispensable á los pueblos débiles para no descender a las ruindades del utilitarismo, é imponer respeto á los Quijotes de la gloria militar. 